\title{
Uric Acid: Friend or Foe?
}

\author{
Azfar $\mathrm{WS}^{\mathrm{a}}$, Nor Azlin $\mathrm{Ml}^{\mathrm{b}}$, Rizal $\mathrm{AM}^{\mathrm{c}}$, Othman $\mathrm{H}^{\mathrm{a}}$ \\ ${ }^{a}$ Department of Pathology, Faculty of Medicine, Universiti Kebangsaan Malaysia, Jalan Yaacob Latif, Kuala Lumpur, Malaysia \\ ${ }^{b}$ Department of Obsteterics \& Gynaecology, Faculty of Medicine, Universiti Kebangsaan Malaysia, Jalan Yaacob Latif, Kuala Lumpur, Malaysia \\ ${ }^{c}$ Department of Community Health, Faculty of Medicine, Universiti Kebangsaan Malaysia, Jalan Yaacob Latif, Kuala Lumpur, Malaysia
}

Keywords

Uric acid; pregnancy third trimester;

pregnancy outcome

Corresponding Author

Dr. Wan Muhammad Azfar Wan Shuaib,

Chemical Pathology Unit,

Department of Pathology,

Faculty of Medicine,

Universiti Kebangsaan Malaysia,

Pusat Perubatan Universiti Kebangsaan

Malaysia,

Kuala Lumpur Malaysia

Tel. No: +603-91459483

E-mail: dr.wmazfar@ukm.edu.my

Received: 26th Sept 2021; Accepted: 4th November 202

Doi: https://doi.org/10.31436/imjm.v21i1

\section{ABSTRACT}

INTRODUCTION: Adverse pregnancy outcomes (APO) continue to trouble physicians worldwide, and uric acid has become a marker of interest in its prediction. Despite this, the correlation of uric acid in the third trimester is rarely studied, and the reference value for normal uric acid levels in pregnancy has yet to be established. This study was conducted to evaluate the association of uric acid levels in the third trimester of pregnancy and the development of APO, specifically gestational hypertension $(\mathrm{GH})$, pre-eclampsia (PE), gestational diabetes mellitus (GDM), small for gestational age (SGA) and to determine the cut-off value of serum uric acid levels for screening of APO.

MATERIALS AND METHODS: A retrospective observational study was conducted among 374 women who delivered at Pusat Perubatan Universiti Kebangsaan Malaysia (PPUKM) and developed APO of interest and had serum uric acid levels taken during the third trimester of pregnancy. A cut-off value of $309 \mu \mathrm{mol} / \mathrm{L}$ was used to assess the sensitivity and specificity in predicting APO. RESULTS: Associations were observed between $309 \mu \mathrm{mol} / \mathrm{L}$ and the development of GH $(\mathrm{p}<0.0005), \mathrm{PE}(\mathrm{p}<0.0005), \mathrm{GDM}$ $(\mathrm{p}<0.0005)$, SGA ( $\mathrm{p}=0.0264)$. Plotted ROC curves with a cut-off point of $309 \mu \mathrm{mol} / \mathrm{L}$ demonstrated moderate predictive value of serum uric acid and the development of $\mathrm{GH}$ (AUC 0.639), PE (AUC 0.713), SGA (AUC 0.649), and low predictive value for GDM

(AUC 0.4). CONCLUSION: Serum uric acid level of $309 \mu \mathrm{mol} / \mathrm{L}$ in the third trimester of pregnancy is a moderate predictor of GH, PE, SGA and a poor predictor of GDM.

\section{INTRODUCTION}

Adverse pregnancy outcomes (APO) among mothers and foetus continue to challenge obstetricians and paediatricians worldwide. Among the APO include gestational hypertension $(\mathrm{GH})$, pre-eclampsia (PE), gestational diabetes mellitus (GDM), and small for gestational age (SGA) babies. Recently serum uric acid levels have been highlighted to be associated with various APO. Studies have shown that elevated levels of uric acid have deleterious effects on the human body. Zhu et al. ${ }^{1}$ found that high uric acid levels inhibit insulin signalling and directly cause insulin resistance, whilst Khosla et al. ${ }^{2}$ demonstrated that high insulin levels could lead to endothelial dysfunction, causing decrease in nitric oxide production. This concurs with an animal study which stated that in animals, nitric oxide is needed for glucose uptake, hence its deficiency leads to hyperglycaemia. ${ }^{3}$
It is reported that hyperuricaemia plays an important role in abnormal placental implantation. High levels of uric acid induce endothelial dysfunction, inflammation \& oxidative stress. ${ }^{4}$ Endothelial dysfunction leads to decrease nitric oxide production. Low nitric oxide levels lead to dysregulation of trophoblastic invasion and inhibit the physiological transformation of spiral arteries, which can lead to PE.

Mador et al. ${ }^{5}$ hypothesized that high uric acid levels in maternal circulation reflect its level in foetal circulation. The elevated uric acid levels in foetal circulation inhibit system A amino acid uptake and trigger endogenous signalling properties of uric acid in foetal tissue, hence suppression of growth rate. They also postulated that uric acid reacts directly with endothelial nitric oxide, thereby 
depleting it and leading to endothelial dysfunction, PE, and eclampsia.

With regards to the reference interval of uric acid levels in pregnancy, no consensus has been agreed upon on the values, however there were efforts made by some studies to establish the reference intervals between the different trimesters. Greer et al. ${ }^{6}$ managed to tabulate reference intervals for various analytes between the different trimesters which included uric acid levels whereby the first trimester ranged from $119-250 \mu \mathrm{mol} / \mathrm{L}$, second trimester from $143-292 \mu \mathrm{mol} / \mathrm{L}$ and the third trimester from $184-375 \mu \mathrm{mol} / \mathrm{L}$. Yuhua Gao et al. ${ }^{7}$ managed to establish trimesteric reference intervals for uric acid by non-parametric methods at their centre where the first trimester values ranged from $122-297 \mu \mathrm{mol} / \mathrm{L}$, second trimester from $129-327 \mu \mathrm{mol} / \mathrm{L}$ and the third trimester from $147-376 \mu \mathrm{mol} / \mathrm{L}$.

In normal pregnancy, serum uric acid levels are expected to reduce by $25-30 \%$ during early pregnancy and increase as pregnancy progresses before decreasing to prepregnancy levels as the end of pregnancy approaches. ${ }^{8}$ Altered renal handling has been proposed to be the cause for these pregnancy-linked changes. Many studies regarding serum uric acid levels in pregnancy and the development of APO mainly focused on the first and second trimester of pregnancy. To date, no consensus regarding standard reference intervals of uric acid in pregnancy has been agreed. Thus, this study investigated the association of uric acid levels in the third trimester of pregnancy and the development of APO, specifically GH, PE, GDM, SGA, and to determine a suitable cut-off value of serum uric acid levels for screening of the APO.

\section{MATERIALS AND METHODS}

This was a retrospective observational study conducted in Pusat Perubatan Universiti Kebangsaan Malaysia (PPUKM), a tertiary hospital in Kuala Lumpur, Malaysia, over three years. Recruitment into the study encompasses the inclusion criteria of all women who delivered at the hospital between $1^{\text {st }}$ January 2016 and 31 ${ }^{\text {st }}$ December 2018, had serum uric acid levels measured during the third trimester, and developed at least one APO. Exclusion criteria were multiple gestation pregnancy, gouty arthritis disease, chronic kidney disease (CKD), Systemic Lupus Erythematosus (SLE), chronic hypertension, and postdated deliveries. Patient details were obtained from the Integrated Laboratory Management System (ILMS) and in -house patient's medical record system (c-HETS). Individual case notes were reviewed for clinical progression and APO development. The predictive value of elevated serum uric acid levels in the third trimester and the development of APO (GH, PE, GDM, SGA) were assessed.

A cut-off value of $309 \mu \mathrm{mol} / \mathrm{L}$ recommended based on a study by Bellomo et al. ${ }^{9}$ was used to observe its sensitivity and specificity in developing APO among the study recruits. Primary outcome measures were APO (GH, PE, GDM, SGA). Secondary outcome measures were the uric acid cut-off value and the cut-off value's sensitivity and specificity. GH is defined as systolic blood pressure (SBP) of $\geq 140 \mathrm{mmHg}$ and/or diastolic blood pressure (DBP) of $\geq 90 \mathrm{mmHg}$ detected for the first time after 20 weeks of gestation. ${ }^{10} \mathrm{PE}$ is clinically diagnosed by the presence of de novo hypertension after 20 weeks of gestation with one or more of the following viz. significant proteinuria, renal insufficiency (serum creatinine $\geq$ $90 \mu \mathrm{mol} / \mathrm{L}$ or oliguria), liver disease (raised transaminases or severe right upper quadrant pain or epigastric pain), neurological problems (altered mental status, hyperreflexia, severe headache), haematological disturbances (thrombocytopenia, coagulopathy), and foetal growth restriction. ${ }^{10} \mathrm{GDM}$ is defined as glucose intolerance of variable degree with onset or first recognition during pregnancy. ${ }^{11} \mathrm{SGA}$ is defined as infants with birth weight (BW) below the 10th percentile for

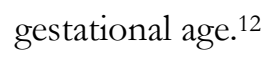

The sample size calculation for this clinical study was performed using the prevalence formula by Jingli et al. ${ }^{13}$ as presented below. A total of 374 samples were finalized after factoring in a $20 \%$ possible dropout.

Serum uric acid was measured using the Uricase method by ARCHITECT c16000 analyzer (Abbott Diagnostics, 


$$
n=\frac{z^{2} P(1-P)}{d^{2}}
$$

$\mathrm{n}=$ sample size

$\mathrm{Z}=\mathrm{Z}$ statistic for a level of confidence (for level of confidence $95 \%, \mathrm{Z}$ value is 1.96 )

$\mathrm{P}=$ expected prevalence or proportion (in proportion of 1 , if $20 \%, \mathrm{P}=0.02$ )

$\mathrm{d}=$ precision (in proportion of 1, if $5 \%, \mathrm{~d}=0.05$ )

Abbott Laboratories, Illinois, United States) in our hospital chemical pathology laboratory with MS ISO 15189 accreditation.

\section{Ethical statement}

The study received approval from the UKM Research Ethics Committee (FF-2019-262)

\section{Statistical analysis}

Non-normally distributed continuous variables were expressed as median and interquartile range (IQR). Pearson's chi-square test of independence was used to assess the association of serum uric acid level cut-off point of $309 \mu \mathrm{mol} / \mathrm{L}$ and the development of each APO of the study. Statistical significance was defined as $\mathrm{p}$-value $<0.05$. Receiver Operating Characteristic (ROC) curve was plotted for each APO, and the area under the curve (AUC) was measured to investigate the value of elevated third-trimester serum uric acid levels and the development of APO (GH, PE, GDM, SGA). The cut-off point of $309 \mu \mathrm{mol} / \mathrm{L}$ was also plotted on each ROC curve to assess the sensitivity and specificity. All statistical analyses were performed using IBM Statistical Package for the Social Sciences (SPSS) for Windows Version 26.0 (IBM Corp., Armonk, NY)

\section{RESULTS}

A total of 374 women were recruited into the study. The demographics of the recruits are displayed in Table I. $75.0 \%$ of recruits had GH, 30.2\% had PE, $42.2 \%$ had GDM, 9.1\% had SGA babies. 61.8\% had serum uric acid levels of $\geq 309 \mu \mathrm{mol} / \mathrm{L}$.

An association was observed between serum uric acid levels of $\geq 309 \mu \mathrm{mol} / \mathrm{L}$ and the development of $\mathrm{GH}$. Among recruits whose uric acid levels were $\geq 309 \mu \mathrm{mol} / \mathrm{L}$,

\begin{tabular}{|c|c|}
\hline Characteristics & n (\%) \\
\hline Age in years & $32(29-36)^{*}$ \\
\hline \multicolumn{2}{|l|}{ Parity } \\
\hline Nulliparous & $139(37.2)$ \\
\hline Multiparous & $235(62.8)$ \\
\hline \multicolumn{2}{|l|}{ Ethnicity } \\
\hline Malay & $293(78.3)$ \\
\hline Chinese & $44(11.8)$ \\
\hline Indian & $11(2.9)$ \\
\hline Others & $10(2.7)$ \\
\hline Foreigners & $16(4.3)$ \\
\hline \multicolumn{2}{|l|}{$\begin{array}{l}\text { Gestation at which uric acid levels } \\
\text { were taken }\end{array}$} \\
\hline $28 w k s$ (<203 days) & $10(2.7)$ \\
\hline $29 \mathrm{wks}(<210$ days $)$ & $20(5.3)$ \\
\hline 30 wks $(<217$ days $)$ & $10(2.7)$ \\
\hline 31 wks (<224 days) & $11(2.9)$ \\
\hline 32 wks (<231 days) & $14(3.7)$ \\
\hline 33 wks (<238 days $)$ & $23(6.1)$ \\
\hline 34 wks $(<245$ days $)$ & $19(5.1)$ \\
\hline 35 wks (<252 days) & $24(6.4)$ \\
\hline $36 w k s(<259$ days $)$ & $37(9.9)$ \\
\hline 37 wks ( $<266$ days $)$ & $76(20.3)$ \\
\hline $38 w k s$ ( $<273$ days $)$ & $71(19.0)$ \\
\hline 39 wks $(<280$ days $)$ & $53(14.2)$ \\
\hline 40wks (280 days) & $6(1.6)$ \\
\hline \multicolumn{2}{|l|}{ Gestational age at delivery } \\
\hline$<34$ weeks & $26(6.9)$ \\
\hline $34-<37$ weeks & $79(21.1)$ \\
\hline $37-40$ weeks & $269(72.0)$ \\
\hline \multicolumn{2}{|l|}{ Mode of delivery } \\
\hline Spontaneous Vaginal Delivery (SVD) & $189(50.5)$ \\
\hline Elective LSCS & $22(5.9)$ \\
\hline Emergency LSCS & $163(43.6)$ \\
\hline \multicolumn{2}{|l|}{ Adverse Pregnancy Outcomes (APO) } \\
\hline Gestational Hypertension (GH) & $281(75.1)$ \\
\hline Pre-eclampsia (PE) & $113(30.2)$ \\
\hline Gestational Diabetes Mellitus (GDM) & $158(42.2)$ \\
\hline Small for gestational age (SGA) & $34(9.1)$ \\
\hline \multicolumn{2}{|l|}{ Number of APO } \\
\hline Single APO & $211(56.4)$ \\
\hline$>1 \mathrm{APO}$ & $163(43.6)$ \\
\hline
\end{tabular}

$82.2 \%$ developed $\mathrm{GH}$; of recruits whose uric acid levels were $<309 \mu \mathrm{mol} / \mathrm{L}, 63.6 \%$ developed $\mathrm{GH} ;(\mathrm{P}<0.0005)$, Table II. An association was also observed between uric acid levels of $\geq 309 \mu \mathrm{mol} / \mathrm{L}$ and the development of PE. Among recruits whose uric acid levels were $\geq 309 \mu \mathrm{mol} / \mathrm{L}$, $39.4 \%$ developed PE, whereby those with uric acid levels $<309 \mu \mathrm{mol} / \mathrm{L}, 15.4 \%$ developed PE; (P<0.0005), Table II. A similar observation was noted between uric acid levels of $\geq 309 \mu \mathrm{mol} / \mathrm{L}$ and the development of GDM, whereby 34.6\% developed GDM. For those recruits whose uric acid levels were $<309 \mu \mathrm{mol} / \mathrm{L}, 54.5 \%$ 
developed GDM (P<0.0005), Table II. Association was also observed with small for gestational age (SGA) where $11.7 \%$ of recruits with serum uric acid levels $\geq 309 \mu \mathrm{mol} /$ $\mathrm{L}$ delivered SGA babies, and those with serum uric acid levels $<309 \mu \mathrm{mol} / \mathrm{L}, 4.9 \%$ had SGA babies. ( $\mathrm{P}=0.0264)$, Table II.

Table II: Association between cut-off serum uric acid levels $\geq 309 u \mathrm{~mol} / \mathrm{L}$ and the development of studied APO among participants

\begin{tabular}{|c|c|c|c|}
\hline \multirow{2}{*}{$\begin{array}{l}\text { Adverse } \\
\text { Pregnancy } \\
\text { Outcomes }\end{array}$} & \multicolumn{2}{|c|}{ Uric Acid Values } & \multirow{2}{*}{$\begin{array}{l}\text { Chi-square test of } \\
\text { independence }\end{array}$} \\
\hline & $\geq 309 \mu \mathrm{mol} / \mathrm{L}$ & $<309 \mu \mathrm{mol} / \mathrm{L}$ & \\
\hline \multicolumn{4}{|c|}{$\begin{array}{l}\text { Gestational } \\
\text { Hypertension }\end{array}$} \\
\hline Yes & 190 & 91 & $\chi^{2}(1, N=374)=$ \\
\hline No & 41 & 52 & $\begin{array}{c}16.38 \\
\mathrm{p}<0.0005\end{array}$ \\
\hline \multicolumn{4}{|c|}{ Pre-eclampsia } \\
\hline Yes & 91 & 22 & $\chi^{2}(1, N=374)=$ \\
\hline No & 140 & 121 & $\begin{array}{c}24.15 \\
p<0.0005\end{array}$ \\
\hline \multicolumn{4}{|l|}{$\begin{array}{l}\text { Gestational } \\
\text { Diabetes } \\
\text { Mellitus }\end{array}$} \\
\hline Yes & 80 & 78 & $\begin{array}{c}\chi^{2}(1, N=374)= \\
14.35\end{array}$ \\
\hline No & 151 & 65 & $\mathrm{p}<0.0005$ \\
\hline \multicolumn{4}{|c|}{$\begin{array}{l}\text { Small for } \\
\text { Gestational Age }\end{array}$} \\
\hline Yes & 27 & 7 & $\chi^{2}(1, N=374)=$ \\
\hline No & 204 & 136 & $p=0.0264$ \\
\hline
\end{tabular}

$\chi^{2}=$ chi square value, $\mathrm{N}=$ sample size, $\mathrm{p}=\mathrm{p}$ value

The plotted ROC curves demonstrate the moderate predictive value of third-trimester serum uric acid levels and the development of GH, PE, SGA, and low predictive value for GDM, Figure 1.

\section{DISCUSSION}

This study investigated the association between raised serum uric acid levels and the development of APO among pregnant women in the third trimester of pregnancy. We chose to study the third trimester as most studies focused on the first and second trimester, yet the third trimester is as equally important. By having a cut-off value in the third trimester, we would be able to identify pregnant women at risk of developing certain APO, especially among unregistered/unrecorded pregnancies presenting in the third trimester, which is quite significant, especially among foreigners from less developed countries.

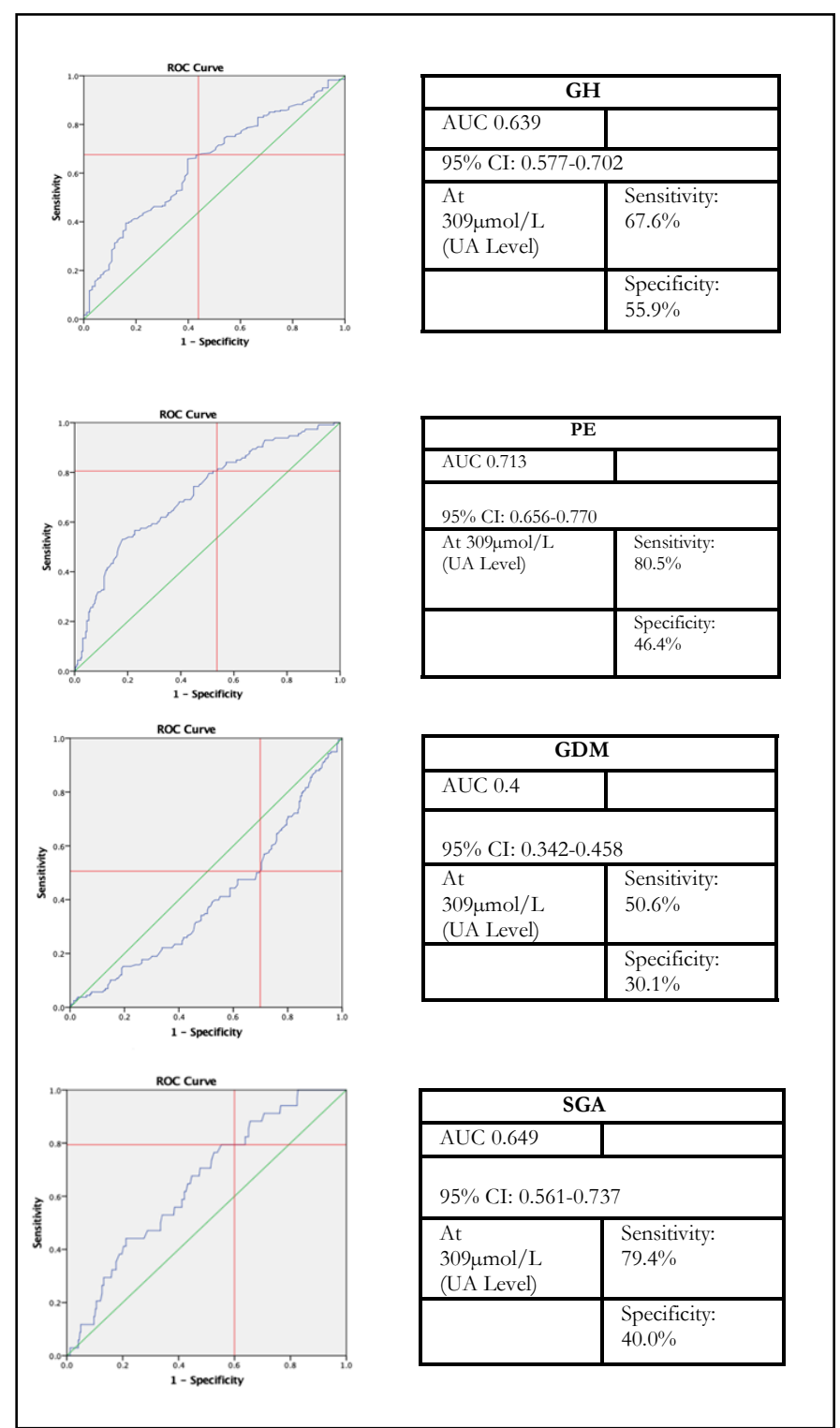

ROC, Receiver Operating Characteristic; AUC, Area Under Curve; CI, Confidence Interval; GH, Gestational Hypertension; PE, Pre-eclampsia; GDM, Gestational Diabetes Mellitus; SGA, Small for Gestational Age

Figure 1: ROC curve and AUC for third-trimester serum uric acid in predicting $G H$ PE, GDM, SGA

We found that raised serum uric acid levels in the third trimester were an important indicator for developing $\mathrm{GH}$, PE, and SGA but a poor indicator for GDM. Other studies have also demonstrated similar findings of raised uric acid levels and the development of APO; Niyonzima et al. ${ }^{14}$ reported in a cross-sectional study conducted amongst 80 pregnant women in Rwanda of different gestations mean uric acid levels were $7.12 \mathrm{mg} / \mathrm{dL}$ $(423.5 \mu \mathrm{mol} / \mathrm{L})$ in the gestational hypertensive group compared to $4.49 \mathrm{mg} / \mathrm{dL}(267.07 \mu \mathrm{mol} / \mathrm{L})$ in the nonhypertensive group. They concluded that the association of hypertension and hyperuricemia was recorded with a 
strong correlation between blood pressure and serum uric acid levels. In another cross-sectional study, Lisnawati et al. ${ }^{15}$ described that amongst 704 pregnant women in Indonesia whose serum uric acid levels were taken immediately before delivery revealed median serum uric levels of $4.9 \mathrm{mg} / \mathrm{dL} \quad(291.45 \mu \mathrm{mol} / \mathrm{L})$ among the gestational hypertension group, $5.18 \mathrm{mg} / \mathrm{dL}$ $(308.11 \mu \mathrm{mol} / \mathrm{L})$ among the pre-eclampsia without complications group and $7.6 \mathrm{mg} / \mathrm{dL}(452.05 \mu \mathrm{mol} / \mathrm{L})$ among severe pre-eclampsia with organ involvement group. They concluded that maternal blood uric acid levels increased significantly, accompanying the severity of hypertensive disorders in pregnancy. Ugwuanyi et al. ${ }^{16}$ described amongst 102 pregnant women with a period of gestation of more than 20 weeks revealed mean serum uric acid levels among the pre-eclamptic group to be higher at $6.08 \mathrm{mg} / \mathrm{dL}(361.64 \mu \mathrm{mol} / \mathrm{L})$ compared the control group $5.2 \mathrm{mg} / \mathrm{dL}(309.3 \mu \mathrm{mol} / \mathrm{L})$. They also found that women with elevated serum uric acid levels $>6 \mathrm{mg} /$ $\mathrm{dL}(356.88 \mu \mathrm{mol} / \mathrm{L})$ were found to be four times more likely to have severe pre-eclampsia, 66 times more likely to deliver babies with APGAR score $<7$ in the first minute and three times more likely to deliver babies with lower birth weight than those with normal serum uric acid levels. It was concluded from their study that mean serum uric acid levels in a pre-eclamptic woman is higher than that of normal pregnant control, and higher levels are associated with severity of the disease and significantly associated with poorer perinatal outcome. In a cross-sectional study conducted in Nepal amongst 90 pregnant women between 24 to 36 weeks of gestation, mean serum uric acid levels were higher in the pregnancyinduced hypertension group compared to the control group; $5.46 \mathrm{mg} / \mathrm{dL}(324.8 \mu \mathrm{mol} / \mathrm{L})$ versus $4.03 \mathrm{mg} / \mathrm{dL}$ $(239.7 \mu \mathrm{mol} / \mathrm{L})^{17}$. Ahmad et al. ${ }^{18}$ reported that amongst 100 pregnant women who developed pre-eclampsia and serum uric acid was taken at mean gestational age of 33.5 weeks, had mean uric acid levels of $7.01 \mathrm{mg} / \mathrm{dL}$ $(417 \mu \mathrm{mol} / \mathrm{L})$. A meta-analysis on the prognostic role of serum uric acid in pre-eclampsia ${ }^{19}$ included 196 studies involving 39540 women, found that higher uric acid was estimated for severe pre-eclampsia, eclampsia, haemolysis, elevated liver enzymes, and low platelet syndrome. They concluded that serum uric acid levels were increased in pre-eclampsia and can be used to predict disease severity and pregnancy complications. Akahori et al. ${ }^{20}$ reported a mean serum uric acid value of $0.31 \mathrm{mmol} / \mathrm{L}(310 \mu \mathrm{mol} / \mathrm{L})$ amongst pregnant women whose uric acid were taken before delivery (mean gestational age 36.3 weeks), delivered severe SGA babies. Zhaoet al. ${ }^{21}$ studied 364 singleton pregnant women with initial presentation of gestational hypertension and found that a cut-off value of $303 \mu \mathrm{mol} / \mathrm{L}$ moderately predicts the outcome of SGA babies. All these studies were in agreement with our findings. However, a systematic review and meta-analysis by Pecoraro et al. ${ }^{22}$ concluded that after narrowing down to 21 studies involving more than 6000 women, no robust evidence currently exists to suggest that uric acid measurement is useful in predicting maternal and perinatal adverse outcomes.

As for the association between serum uric acid and GDM, there was less data than other APO. Yan Zhao et al.23, in their cohort study of 85609 pregnant Chinese ladies, found that the risk of GDM was significantly higher among pregnant women whose uric acid levels were between $203-412 \mu \mathrm{mol} / \mathrm{L}$ and between 13-18 weeks of gestation. Rehman et al. ${ }^{24}$ reported in their study of 172 pregnant women in the first trimester of pregnancy where mean uric acid levels of GDM mothers were higher compared to the control group; $3.73 \mathrm{mg} / \mathrm{dL}(221.9 \mu \mathrm{mol} /$ L) vs. $3.19 \mathrm{mg} / \mathrm{dL}(189.74 \mu \mathrm{mol} / \mathrm{L})$. Li et al. ${ }^{25}$, in their study of 1769 pregnant women, also reported that GDM group mothers had higher mean serum uric acid levels than non-GDM mothers $(216.45 \mu \mathrm{mol} / \mathrm{L}$ vs. $209.36 \mu \mathrm{mol} /$ L). They concluded that higher uric acid levels and a higher composite kidney function biomarker score during the 16-18th week of gestation were positively and independently associated with an increased risk of GDM. Ganta et al.26, in their prospective study of 312 pregnant women, found that the serum uric acid cut-off level of $3.5 \mathrm{mg} / \mathrm{dL}(208.18 \mu \mathrm{mol} / \mathrm{L})$ had great sensitivity and specificity in predicting GDM when measured at 12 and 24 weeks of gestation. El-Gharib et al. ${ }^{27}$, in their study of 250 women in the first trimester of pregnancy with elevated uric acid concentration $>4 \mathrm{mg} / \mathrm{dl}(238 \mu \mathrm{mol} / \mathrm{L})$, $48.8 \%$ developed GDM. They recommended that serum uric acid measurement be done as a routine test during the first antenatal visit. Wolak et al. ${ }^{28}$ also reported that elevated serum uric acid levels in the first 20 weeks of 
pregnancy are associated with a higher risk for the development of GDM. Aparna ${ }^{29}$ reported in her study of 225 women, a cut-off serum uric acid level of $3.4 \mathrm{mg} / \mathrm{dL}$ $(202.23 \mu \mathrm{mol} / \mathrm{L})$ before 20 weeks of gestation was found to have a sensitivity of $90 \%$, specificity of $95 \%$, a positive predictive value of $50 \%$, and a negative predictive value of $99 \%$ for the development of GDM. These studies demonstrated the association of uric acid as a marker for screening of GDM; however, they focussed mainly on the utility of uric acid during the first and second trimesters.

We used the cut-off value of $309 \mu \mathrm{mol} / \mathrm{L}$ based on the study by Bellomo et al. ${ }^{9}$ They demonstrated that amongst pregnant women with a mean time of presentation at 34 weeks (third trimester), elevated serum uric acid conferred an 8-to-9-fold risk for pre-eclampsia and a 1.6to-1.7-fold risk for delivering small for gestational age babies and that the cut-off value also conferred excellent sensitivity, specificity, and likelihood ratios for diagnosis and prognosis. The cut-off value was lower than that suggested by Hawkins et al. ${ }^{30}$ of $5.6 \mathrm{mg} / \mathrm{dL}(333.1 \mathrm{mmol} /$ L), Ryu et al. ${ }^{31}$ at $377.7 \mu \mathrm{mol} / \mathrm{L}$, Le et al. ${ }^{32}$ at $393 \mu \mathrm{mol} / \mathrm{L}$ and Goad et al. ${ }^{33}$ at $417 \mu \mathrm{mol} / \mathrm{L}$ (Table III). From our findings, the cut-off value of $309 \mu \mathrm{mol} / \mathrm{L}$ gives moderate sensitivity and specificity for the development of APO. When we compared our findings with the study by Bellomo et al.,9 our sensitivity for developing PE and SGA was high at $80.5 \%$ and $79.4 \%$, but specificity was low at $46.4 \%$ and $40 \%$, respectively. At the cut-off value of $309 \mu \mathrm{mol} / \mathrm{L}$, moderate sensitivity and specificity were seen for GH and low for GDM.

\begin{tabular}{|c|c|c|c|c|c|c|c|c|}
\hline \multirow[t]{2}{*}{$\begin{array}{l}\text { Uric Acid } \\
\text { cut-off values }\end{array}$} & \multicolumn{2}{|c|}{$\begin{array}{l}\text { Gestational } \\
\text { Hypertension (GH) }\end{array}$} & \multicolumn{2}{|c|}{ Pre-eclampsia (PE) } & \multicolumn{2}{|c|}{$\begin{array}{l}\text { Gestational Diabetes } \\
\text { Mellitus (GDM) }\end{array}$} & \multicolumn{2}{|c|}{$\begin{array}{l}\text { Small for Gestational } \\
\text { Age (SGA) }\end{array}$} \\
\hline & Sen $(\%)$ & Spe (\%) & Sen $(\%)$ & Spe (\%) & Sen $(\%)$ & Spe (\%) & Sen $(\%)$ & Spe $(\%)$ \\
\hline 309.0 & $67.6 \%$ & $55.9 \%$ & $80.5 \%$ & $46.4 \%$ & $50.6 \%$ & $30.1 \%$ & $79.4 \%$ & $40.0 \%$ \\
\hline 333.1 & $51.6 \%$ & $64.5 \%$ & $67.3 \%$ & $60.9 \%$ & $39.9 \%$ & $46.8 \%$ & $67.6 \%$ & $54.4 \%$ \\
\hline 377.7 & $31.7 \%$ & $87.1 \%$ & $50.4 \%$ & $83.1 \%$ & $19.6 \%$ & $67.6 \%$ & $44.1 \%$ & $74.7 \%$ \\
\hline 393.0 & $27.0 \%$ & $89.2 \%$ & $43.4 \%$ & $85.8 \%$ & $17.7 \%$ & $73.1 \%$ & $41.2 \%$ & $78.8 \%$ \\
\hline 417.0 & $19.2 \%$ & $92.5 \%$ & $31.9 \%$ & $88.9 \%$ & $12.7 \%$ & $81.0 \%$ & $29.4 \%$ & $85.0 \%$ \\
\hline
\end{tabular}

At a cut-off value of $309 \mu \mathrm{mol} / \mathrm{L}$, our findings demonstrated better sensitivity and specificity than the other studies' cut-off values, Table III. Although our sensitivity was good for PE and SGA, the specificity was relatively low. We postulated that factors like demographics of the study population, dietary habits, and lifestyle could have potentially affected the outcome, as shown in the study by Beydoun et al. ${ }^{34}$ It could also indicate that uric acid as a sole marker for predicting APO might not be sufficient and requires additional supportive markers; however, as a screening marker, it confers excellent sensitivity.

The association between serum uric acid and GDM was not powerfully demonstrated in this study. We believed this could be due to the high prevalence of GDM in our population; hence a bigger sample size might be needed to assess the association of uric acid levels and the development of GDM.
The strength of this study lies with it being conducted amongst third-trimester pregnant women, where most studies had focused on pregnant women in the first trimester. Secondly, strict exclusion criteria were implemented to reduce the impact of confounding factors.

Limitation of the study includes being retrospective and being conducted at only one tertiary centre hence may not represent the country's population. Another limitation is that no consensus has been agreed upon regarding the specific gestation or days within the third-trimester uric acid should be taken. Apart from that, some pregnant women developed more than one APO, and the possibility of the results being affected by a combination of APO cannot be excluded. Regarding GDM, a higher sample size might be needed due to the high prevalence of GDM among pregnant women, which could give a different depiction. 
Studies in the future should include a broader population with well-coordinated multicentric involvement and include agreed uric acid thresholds with certain gestational days or weeks in the third trimester to provide a more comprehensive and collective view of the research. We also believe that for future studies, more significant recruits should be incorporated and tailored to GDM as the sole APO could probably give a better insight into the utility of uric acid in the third trimester with GDM. As of current practice, uric acid is not typically taken to monitor the progress of GDM in pregnancy. We hope that in the future, it can be utilized for GDM monitoring as well.

\section{CONCLUSION}

This study demonstrated that serum uric acid levels in the third trimester of pregnancy, particularly at the cut-off point of $309 \mu \mathrm{mol} / \mathrm{L}$, is a moderate predictor of $\mathrm{GH}, \mathrm{PE}$, and SGA and a poor predictor of GDM. We also conclude that uric acid levels in the third trimester are as equally important as the levels in the first and second trimester of pregnancy. With this uric acid cut-off level, we hope that clinicians will have an early alert when an undocumented/unrecorded third-trimester pregnant patient arrives at the health facility.

\section{DISCLOSURE}

All authors participated in the data collection and analysis and approved the final version submitted. All authors declare no conflict of interest. No funding was received in this study.

\section{ACKNOWLEDGMENTS}

The authors wish to thank the Medical Record Unit of the Health Information Department of PPUKM, HCTM, and related parties for their assistance in providing access to the clinical notes for conducting this study.

\section{REFERENCES}

1. Zhu Y, Hu Y, Huang T, Zhang Y, Li Z, Luo C, et al. High uric acid directly inhibits insulin signalling and induces insulin resistance. Biochem Biophys Res Commun. 2014;447(4):707-14.

2. Khosla UM, Zharikov S, Finch JL, Nakagawa T, Roncal C, Mu W, et al. Hyperuricemia induces endothelial dysfunction. Kidney Int. 2005;67(5):1739 -42 .

3. Ridnour LA, Isenberg JS, Espey MG, Thomas DD, Roberts DD, Wink DA. Nitric oxide regulates angiogenesis through a functional switch involving thrombospondin-1. Proc Natl Acad Sci. 2005;102 (37):13147-52.

4. Sultana R, Ahmed S, Sultana N, Karim SMF, Atia F. Original Article Association of Serum Uric Acid with Preeclampsia : A Case Control Study. 2013;1(2).

5. Mador ES, Pam IC, Isichei CO. Uric acid: A hypothetical cause of preeclampsia-eclampsia. Niger Med J. 2013;54(5):362-4.

6. Greer LG. A Reference Table for Clinicians. 2009;114(6):1326-31.

7. Gao Y, Jia J, Liu X, Guo S, Ming L. TrimesterSpecific Reference Intervals of Serum Urea, Creatinine, and Uric Acid Among Healthy Pregnant Women in Zhengzhou, China. Lab Med. 2021;52 (3):267-72.

8. Lind T, Godfrey KA, Otun H, Philips PR. Changes in serum uric acid concentrations during normal pregnancy. BJOG An Int J Obstet Gynaecol. 1984;91 (2):128-32.

9. Bellomo G, Venanzi S, Saronio P, Verdura C, Narducci PL. Prognostic significance of serum uric acid in women with gestational hypertension. Hypertension. 2011;58(4):704-8.

10. Tranquilli AL, Dekker G, Magee L, Roberts J, Sibai BM, Steyn W, et al. The classification, diagnosis and management of the hypertensive disorders of pregnancy: A revised statement from the ISSHP. Pregnancy Hypertens. 2014;4(2):97-104. 
11. Karagiannis T, Bekiari E, Manolopoulos K, Paletas K, Tsapas A. Gestational diabetes mellitus: Why screen and how to diagnose. Hippokratia. 2010;14 (3):151-4.

12. RCOG. The Investigation and Management of the Small-for-Gestational-Age Fetus. Green-top Guideline No. 31. 2013;(31):34.

13. Liu J, Xu B, Chen T, Chen J, Feng J, Xu C, et al. Presence of hepatitis B virus markers in umbilical cord blood: Exposure to or infection with the virus? Dig Liver Dis. 2019;51(6):864-9.

14. Niyongabo Niyonzima F, Dusabimana A, Berchmas Mutijima J. Pregnancy Induced Hypertension and Uric Acid Levels among Pregnant Women Attending Ruhengeri Referral Hospital, in Rwanda. East African Heal Res J. 2021;5(1):44-9.

15. Lisnawati Y, Berguna JSN, Irwinda R, Wati KA, Nurfauziah N. A significant increase in maternal blood uric acid levels accompanies the severity of hypertensive disorders in pregnancy. Indones J Obstet Gynecol. 2021;9(3):144-8.

16. Ugwuanyi RU, Chiege IM, Agwu FE, Eleje GU, Ifediorah NM. Association between Serum Uric Acid Levels and Perinatal Outcome in Women with Preeclampsia. Obstet Gynecol Int. 2021;6611828

17. Niraula A, Lamsal M, Majhi S, Khan SA, Basnet P. Significance of Serum Uric Acid in Pregnancy Induced Hypertension. J Natl Med Assoc. 2017;109 (3):198-202.

18. Ahmed QN, Dewan F. Effect of raised serum uric acid level on perinatal and maternal outcome in cases of pregnancy-induced hypertension. Bangabandhu Sheikh Mujib Med Univ J. 2017 May 22;10(2):58.

19. Bellos I, Pergialiotis V, Loutradis D, Daskalakis G. The prognostic role of serum uric acid levels in preeclampsia: A meta-analysis. J Clin Hypertens. 2020;22(5):826-34.

20. Akahori Y, Masuyama H, Hiramatsu Y. The correlation of maternal uric acid concentration with small-for-gestational-age fetuses in normotensive pregnant women. Gynecol Obstet Invest. 2012;73 (2):162-7.

21. Zhao X, Frempong ST, Duan T. Uric acid levels in gestational hypertensive women predict pre- eclampsia and outcome of small-for-gestational-age infants. J Matern Neonatal Med. 2021;34(17):282531.

22. Pecoraro V, Trenti T. Predictive value of serum uric acid levels for adverse maternal and perinatal outcomes in pregnant women with high blood pressure. A systematic review and meta-analysis. Eur J Obstet Gynecol Reprod Biol. 2020;252:447-54.

23. Zhao Y, Zhao Y, Fan K, Jin L. Serum uric acid in early pregnancy and risk of gestational diabetes mellitus : a cohort study of 85, 609 pregnant women Corresponding : Liping Jin. Diabetes Metab. 2021;101293.

24. Rehman A, Saeed S, Hasnny SF et al. Predictive significance of first trimester serum uric acid as risk factor for the gestational diabetes mellitus. Prof Med J. 2021;28(7):967-72.

25. Li Y, Yu T, Liu Z, Chen H, Liu Y, Wei Y, et al. Association of serum uric acid, urea nitrogen, and urine specific gravity levels at 16-18 weeks of gestation with the risk of gestational diabetes mellitus. Diabetes, Metab Syndr Obes Targets Ther. 2020;13:4689-97.

26. Ganta SJ, Kulkarni SR. First trimester uric acid level: a reliable marker for gestational diabetes mellitus. Int J Reprod Contraception, Obstet Gynecol. 2019;8 (6):2358.

27. El-Gharib M, Farahat M, Mahfouz A, Morad M. Prediction of gestational diabetes by measuring first trimester maternal serum uric acid concentration. J Basic Clin Reprod Sci. 2013;2(1):27.

28. Wolak T, Sergienko R, Wiznitzer A, Paran E, Sheiner E. High uric acid level during the first 20 weeks of pregnancy is associated with higher risk for gestational diabetes mellitus and mild pre-eclampsia. Hypertens Pregnancy. 2012;31(3):307-15.

29. Aparna Kappaganthu JSGS. Hyperuricemia in Early Pregnancy A Marker for Gestational Diabetes Mellitus. IOSR J Dent Med Sci. 2014;13(12):51-4

30. Hawkins TLA, Roberts JM, Mangos GJ, Davis GK, Roberts LM, Brown MA. Plasma uric acid remains a marker of poor outcome in hypertensive pregnancy: A retrospective cohort study. BJOG An Int J Obstet Gynaecol. 2012;119(4):484-92. 
31. Ryu A, Cho NJ, Kim YS, Lee EY. Predictive value of serum uric acid levels for adverse perinatal outcomes in pre-eclampsia. Med (United States). 2019;98(18).

32. Le TM, Nguyen LH, Phan NL, Le DD, Nguyen HVQ, Truong VQ, et al. Maternal serum uric acid concentration and pregnancy outcomes in women with pre-eclampsia/eclampsia. Int J Gynecol Obstet. 2019;144(1):21-6.

33. Goad S, Verma A, Chandra S. A Study Of Serum Uric Acid Levels In Preeclampsia. Int J Med Biomed Stud. 2020;4(1):260-1.

34. Beydoun MA, Fanelli-Kuczmarski MT, Canas JA, Beydoun HA, Evans MK, Zonderman AB. Dietary factors are associated with serum uric acid trajectory differentially by race among urban adults. Br J Nutr. 2018;120(8):935-45. 